\section{Lectin binding in normal donkey eyeball}

\section{Khaled Aly \\ Department of Anatomy and Histology, Faculty of Veterinary Medicine, Assiut University, Egypt}

\begin{abstract}
In the present study, the distribution of various sugar residues in the eyeball tissues of sexually mature donkey was examined by employing fluorescein isothiocyanate-conjugated lectins. Our results revealed the presence of mannose (labeled by lectins ConA), galactose (labeled by PNA, GSAI, ECA), GalNAc (labeled by SBA, VVA), and GlcNAc (labeled by WGA) residues in the donkey ocular tissues. The epithelium and stroma of the ocular tissues were labeled with mannose (ConA) and GlcNAc (WGA) binding lectins. Binding sites for WGA and PNA to the rod and cone cells of the retina were evident. The lectins Con A, WGA and GSAI are bound strongly to the endothelium of blood vessels and to smooth muscle cells of the iris. In conclusion, the findings of the present study clearly indicate that the donkey eyeball contains a wide range of glycoconjugates (bearing mannosyl, galactosyl and glucosly residues), and it lacks fucosyl residues.
\end{abstract}

\section{Introduction}

In recent years, lectin histochemistry has developed into a useful tool to study various aspects of cell differentiation and cell-to-cell interaction. ${ }^{1,2}$ As well as the cell surface saccharides believed to be involved in a variety of cell functions including development, growth regulation and cellular locomotion. ${ }^{2-4}$

Significantly, most plant and animal lectins have been classified into a rather limited number of carbohydrate-binding groups. ${ }^{5}$ These include the mannose/glucose-binding lectins, the galactose-binding lectins, the $\mathrm{N}$-acetylgalactosamine-binding lectins, the $\mathrm{N}$-acetylglucosamine-binding lectins, the L-fucosebinding lectins, sialic acid-binding lectins, and lectins with complex carbohydrate-binding sites. In the field of ocular tissue, lectins applied for various purposes to study the differences between normal and migrating corneal epithelium, ${ }^{6}$ and to demonstrate the importance of glycoconjugates in the morphogenesis of the corneoscleral angle where they provide some of the required signals for the differenti- ation of the trabecular meshwork. ${ }^{7}$ Lectins, at light microscopal level, investigate normal

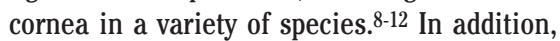
by using this technique, changes in patterns of glycosylation have been observed in wounded and dystrophic corneas. ${ }^{6,13-17}$ Also, they determine the distribution of carbohydrate residues on photoreceptor cell surfaces.12,18 Thus, Blanks and Johnson could demonstrate selective binding-sites for lectins in the developing retina, ${ }^{19}$ as well as specific binding of peanut lectin to certain photoreceptor cells. ${ }^{20}$ These lectin binding patterns of the ciliary body epithelium suggest a topographical and functional difference in this double cell-layered epithelium. ${ }^{21}$ Many studies on monkey, pig, cat and rabbit, and eye tissues were intensely labeled with.22 Lectins are used in eye research mainly for human material. ${ }^{23}$ Lectin histochemistry is considered to be a valuable method for determining changes in the glycoconjugate content during normal and pathological conditions. To our knowledge, no data are available concerning the donkey. Therefore, the aim of present work has been to determine the changes in the sugar residues within the donkey eyeball by means of glycohistochemical (lectin histochemical) methods.

\section{Materials and Methods}

\section{Samples}

The present study was performed on the eyeball of 10 sexually mature and apparently healthy donkeys. Specimens were taken from the cornea, sclera, iris, ciliary body, choroid, retina and optic nerve, with a side length of $0.3-0.5 \mathrm{~cm}$.

All samples were collected within $30 \mathrm{~min}$ from the dissecting room of the Department of Anatomy and Histology and the Teaching Hospital of the Faculty of Veterinary Medicine, Assiut University. All specimens were obtained from adult and clinically healthy animals of both sexes. Small samples of the eyeball tissue $(0.5-1 \mathrm{~cm})$ were fixed in Bouin's fluid for $24 \mathrm{~h}$. Thereafter, fixed samples were extensively washed in 70\% ethanol (3-24 h) to elute fixative before tissue processing to paraffin wax by routine methods. By using a Leitz rotatory microtome (type 1521), 5-mm-thick sections were cut and mounted on both 3- aminopropyltriethoxysilane- coated and uncoated glass slides. Paraffin wax embedded sections were kept in an incubator at $40^{\circ} \mathrm{C}$ until they were used for glycohistochemical analysis.

\section{Lectin histochemistry}

Distribution of sugar moieties (glycoconjugates) in the adult donkey eyeball tissues was investigated through using 9 different fluores-
Correspondence: Khaled Aly, Department of Anatomy and Histology, Faculty of Veterinary Medicine, Assiut University, Assiut, Egypt.

Tel. +20.100.804.7754 - Fax: +20.882 .366 .503$

E-mail: khaledali69@hotmail.com

Key words: lectin, donkey, eyeball.

Received for publication: 4 December 2012. Revision received: 12 March 2013.

Accepted for publication: 12 March 2013.

This work is licensed under a Creative Commons Attribution NonCommercial 3.0 License (CC BYNC 3.0).

(C) Copyright K. Aly, 2013

Licensee PAGEPress srl, Italy

Veterinary Science Development 2013; 3:e7 doi:10.4081/vsd.2013.e7

cein isothiocyanate- (FITC) conjugated lectins, (all purchased from Sigma Aldrich Chemicals $\mathrm{GmbH}$, Deisenhofen, Germany) listed in Table 1. The lectins were chosen to represent five groups: mannose-, galactose-, $\mathrm{N}$-acetylgalactosamine (GalNAc)-, N-acetylglucosamine (GlcNAc)- and fucose-binding lectins. Lectin binding was revealed as follows: sections were dewaxed (2-30 min) in xylene, rehydrated through descending grades of ethanol and washed under tap water for $10 \mathrm{~min}$. They were then washed (3-5 min) in 0.05M Tris-buffer, pH 6.8 and then incubated with $33 \mathrm{mg} / \mathrm{ml}$ FITCconjugated lectin in Tris buffer in a humid chamber, at $4^{\circ} \mathrm{C}$, overnight.

Sections were then again washed under tap water for $5 \mathrm{~min}$ and subsequently rinsed (3-5 min) in Tris buffer ( $\mathrm{pH}$ 6.8). Importantly, the hydrated sections were then taken directly from Tris-buffer and mounted with a 25:140 mixture of polyvinyl alcohol and ethylene glycol (Serva, Heidelberg, Germany) in Tris-buffer, $\mathrm{pH}$ 6.8. Mounted slides were stored at $-20^{\circ} \mathrm{C}$ until examined by using a fluorescent microscope.

\section{Controls}

Control sections were treated as described previously except that the FITC-conjugated lectins were either i) substituted with Trisbuffer, or ii) pre-incubated with $0.4 \mathrm{M}$ of the corresponding hapten sugar inhibitor listed in Table 1 (Sigma, Deisenhofen, Germany) for 1 $\mathrm{h}$ before labeling.

Analysis of labeling Lectin-labeled eyeball tissues and their controls were evaluated by using a Dialux 20 fluorescent microscope (Leitz GmbH, Wetzlar, Germany). Photomicrographs were captured by using Kodak film elite 400 . 


\section{Results}

Slight differences in lectin labeling to reveal different sugar moieties were seen in different ocular tissues. The results are summarized in Table 2 and described in detail below.

\section{Cornea}

As in other species the donkey cornea is composed of five layers, the corneal epithelium, subepithelial basement membrane (Bowman's membrane), substantia propria or stroma, posterior limiting membrane (Descemet's membrane), and posterior epithelium (corneal endothelium).

Con A, WGA and ECA bound to all layer of the cornea, binding of LTA, SBA, VVA, PNA, GSA I and UEAI were observed only in epithelial layer of the cornea (Table 2).

Con A, WGA, ECA and UEA-I reacted strongly with the corneal epithelium (Figure 1), while the others lectin reaction were very weak.

The binding of Con A, WGA, PNA to the Bowman's membrane were strong while the others did not bind significantly.

The corneal stroma, Descemet's membrane and endothelial cells of the cornea reacted mainly with Con A and WGA (Figure 1). Other lectins did not show any reaction or give only a weak reaction (Table 2).

\section{Sclera}

The sclera consists of flat ribbons of collagenous bundles running in various directions. Between these bundles are fine elastic nets, fibroblasts and occasional melanocytes.

As in the other species the donkey sclera can be subdivided into three layers. The outermost layer, the episcleral tissue, consists of loose fibroelastic tissue. In the middle layer, the sclera proper (substantia propria) bundles of collagenous fibers are mainly parallel to the

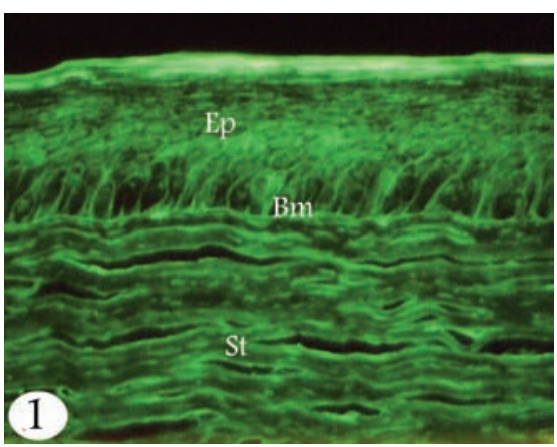

Figure 1. Lablling of the epithelium (Ep), Bowman's membrane $(\mathrm{Bm})$ and stroma (St) of the donkey cornea with WGA $(\times 600)$. the tunica media (Figure 2B). Though the VVA and ECA were bound to all layers of the blood vessels, the staining was not particularly prominent (Figure 2C). GSA I agglutinin is bound strongly to the endothelium of all blood vessels. The reaction appeared clearly because the adjacent stroma was negative.

Con A, WGA and VVA were bound strongly to the sphincter iridal muscles (Figure 2A). Also ECA was bound to it but in a lesser degree. Con $\mathrm{A}$ and ECA were bound strongly to the dilator muscle of the iris. Other lectins did not show any reaction with iridal muscles (Figure 2D,E).

Con A and WGA reacted with the posterior pigmented epithelium of the iris. The reaction was not very strong. Others lectins did not stain the pigmented epithelium at all (Table 2).

\section{Ciliary body}

The donkey ciliary body consists of the following layers; the supraciliaris layer which is the most peripheral layer of the ciliary body, the ciliary muscle, the stroma of the ciliary body that contains a large number of blood ves-
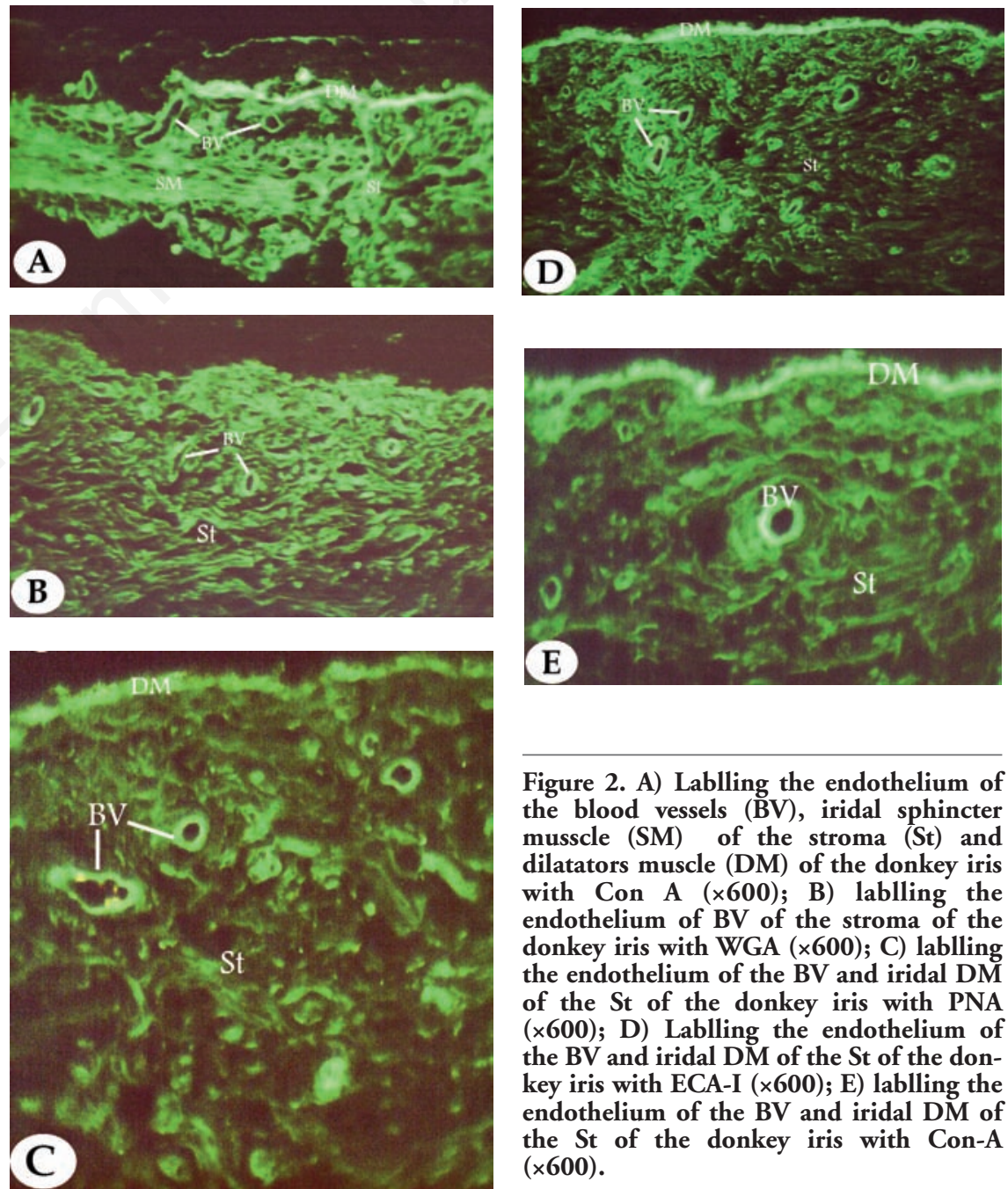

Figure 2. A) Lablling the endothelium of the blood vessels (BV), iridal sphincter musscle (SM) of the stroma (St) and dilatators muscle (DM) of the donkey iris with Con A $(\times 600)$; B) lablling the endothelium of $\mathrm{BV}$ of the stroma of the donkey iris with WGA $(\times 600)$; C) lablling the endothelium of the $\mathrm{BV}$ and iridal DM of the St of the donkey iris with PNA $(\times 600)$; D) Lablling the endothelium of the BV and iridal DM of the St of the donkey iris with ECA-I ( $\times 600)$; E) lablling the endothelium of the $\mathrm{BV}$ and iridal DM of the St of the donkey iris with Con-A (x600). 
sels, arteries and veins, the Bruch's membrane, the pigmented epithelium layer that consists of simple cuboidal or low columnar cells with rounded nuclei and the nonpigmented epithelial layer which is the internal cellular lining of the ciliary body.

Ciliary body of material is connected strongly with Con A and WGA (Figure 3) while ECA and PNA give moderate reaction.
The other lectins do not give any positive reaction with examined materials (Table 2). Con A, WGA and PNA also labelled the smooth muscle cell of the ciliary muscles (Figure 3 ). The nonpigmented layer of the ciliary epithelium bound all lectins except UEA I. Con A, WGA, and PNA showed a stronger binding of different layer of blood vesseles than the other lectins.

\section{Choroid}

The choroideacan be subdivided into four layers as follows; the suprachoroid layer, the perichoroidal spaces, and the vessel layer consisting of intercrossing of large and medium sized arteries and veins, separated by loose connective tissue stroma rich in chromatophores.

Table 1. FITC-labeled lectins are used for investigation of sugar moieties in the donkey ocular tissue.

\begin{tabular}{|c|c|c|c|c|c|}
\hline Lectin group & $\begin{array}{l}\text { Lectin source } \\
\text { (Latin name) }\end{array}$ & $\begin{array}{l}\text { Common } \\
\text { name }\end{array}$ & Acronym & Sugar specificity & $\begin{array}{l}\text { Binding } \\
\text { inhibitor }\end{array}$ \\
\hline D-Mannose (D-Glucose)-binding lectins & Canavalia ensiformis Agglutinin & Jack bean & Con A & $\alpha$-D-Man $>\alpha$-D-Glc & Man \\
\hline D-Galactose-binding lectins & $\begin{array}{l}\text { Arachis hypogaea Agglutinin } \\
\text { Griffonia simplicifolia I Agglutinin } \\
\text { Erythrina Cristagalli Agglutinin }\end{array}$ & $\begin{array}{l}\text { Peanut } \\
\text { Griffonia or Bandeiraea } \\
\text { Coral tree }\end{array}$ & $\begin{array}{l}\text { PNA } \\
\text { GSA-I } \\
\text { ECA }\end{array}$ & $\begin{array}{l}\beta-D-G a l-(1-3)-D-G a l N A c \\
\text { Terminal } \alpha \text {-Gal } \\
\alpha \text {-D-Gal-(1-4)-GlcNAc }\end{array}$ & $\begin{array}{l}\text { Gal } \\
\text { Gal } \\
\text { Gal }\end{array}$ \\
\hline $\begin{array}{l}\mathrm{N} \text {-acetyl-D-galactosamine (GalNAc)- } \\
\text { binding lectins }\end{array}$ & $\begin{array}{l}\text { Glycine max Agglutinin } \\
\text { Visea villosa Agglutinin }\end{array}$ & $\begin{array}{l}\text { Soybean } \\
\text { Hairy vetch }\end{array}$ & $\begin{array}{l}\text { SBA } \\
\text { WA }\end{array}$ & $\begin{array}{l}\text { D-GalNAc } \\
\text { D-GalNAc }\end{array}$ & $\begin{array}{l}\text { GalNAc } \\
\text { GalNAc }\end{array}$ \\
\hline $\begin{array}{l}\text { N-acetyl-D-glucosamine (GlcNAc)- } \\
\text { binding lectins }\end{array}$ & Triticum vulgaris Agglutinin & Wheat germ & WGA & $\begin{array}{l}\text { GlcNAc }(\beta 1-4 \mathrm{GlcNAc}) \\
1-2, \text { NeuNAc }\end{array}$ & GlcNAc \\
\hline L-Fucose-binding lectins & $\begin{array}{l}\text { Ulex europaeus -I Agglutinin } \\
\text { Lotus tetragonolobus Agglutinin }\end{array}$ & $\begin{array}{l}\text { Gorse seed } \\
\text { Asparagus pea }\end{array}$ & $\begin{array}{l}\text { UEA-I } \\
\text { LTA }\end{array}$ & $\begin{array}{l}\alpha \text {-L-Fuc } \\
\alpha \text {-L-Fuc }\end{array}$ & $\begin{array}{l}\alpha \text {-L-Fuc } \\
\alpha \text {-L-Fuc }\end{array}$ \\
\hline
\end{tabular}

Man, mannose; Glc, glucose; Gal, galactose; GalNAc, N-acetylgalactosamine; GlcNAc, N-acetylglucosamine; NeuNAc, N-acetylneuraminic acid (sialic acid); $\alpha$-L-Fuc, $\alpha$-L-Fucose.

Table 2. Lectin binding sites in the donkey eyeball fixed with Bouin's solution.

\begin{tabular}{|c|c|c|c|c|c|c|c|c|c|}
\hline Sites & Con A & LTA & ECA & SBA & VVA & WGA & PNA & GSA I & UEA I \\
\hline \multicolumn{10}{|l|}{ Cornea } \\
\hline Ep & +++ & + & + & $+/-$ & $+/-$ & +++ & +++ & + & ++ \\
\hline $\mathrm{Bm}$ & ++ & - & - & - & - & ++ & ++ & - & - \\
\hline St & ++ & - & $+/-$ & - & - & ++ & $+/-$ & - & - \\
\hline $\mathrm{Dm}$ & ++ & $+/-$ & + & - & $+/-$ & ++ & $+/-$ & - & - \\
\hline En & ++ & + & $+/-$ & $+/-$ & $+/-$ & ++ & $+/-$ & - & - \\
\hline Sclera & - & - & + & - & $+/-$ & $+1-$ & - & - & - \\
\hline
\end{tabular}

\begin{tabular}{|c|c|c|c|c|c|c|c|c|c|}
\hline \multirow{2}{*}{\multicolumn{10}{|c|}{ Iris }} \\
\hline & & & & & & & & & \\
\hline PE & +++ & - & $+/-$ & - & - & $+/++$ & - & - & - \\
\hline St & ++ & - & ++ & - & ++ & ++ & + & - & + \\
\hline BV & $+/++$ & $+/-$ & $+/++$ & $+/-$ & ++ & $+/++$ & ++ & +++ & - \\
\hline SM & ++ & - & + & - & $+/++$ & ++ & - & - & - \\
\hline \multicolumn{10}{|c|}{ Ciliary body } \\
\hline CM & + & - & - & - & - & + & + & - & - \\
\hline NPE & ++ & + & + & + & + & ++ & ++ & + & - \\
\hline
\end{tabular}

\section{Choroid}

\begin{tabular}{|c|c|c|c|c|c|c|c|c|c|}
\hline \multicolumn{10}{|c|}{ Choroid } \\
\hline BL & ++ & - & ++ & - & ++ & ++ & - & - & - \\
\hline BV & ++ & - & ++ & - & ++ & ++ & ++ & ++ & - \\
\hline \multicolumn{10}{|l|}{ Retina } \\
\hline RPE & $++/+++$ & - & - & - & $++/+++$ & $++/+++$ & $++/+++$ & $+/-$ & - \\
\hline$R \& C$ & $++/+++$ & - & - & - & $++/+++$ & $++/+++$ & $++/+++$ & ++ & - \\
\hline ELM & ++ & - & - & - & - & ++ & ++ & - & - \\
\hline ONL & + & - & - & - & - & + & - & - & - \\
\hline OPL & + & - & - & - & - & + & + & - & - \\
\hline INL & + & - & - & - & - & + & - & - & - \\
\hline IPL & + & - & - & - & - & + & + & - & - \\
\hline GCL & + & - & - & - & - & - & - & - & - \\
\hline NFL & + & - & - & - & + & + & + & - & - \\
\hline ILM & ++ & - & - & - & - & ++ & ++ & - & - \\
\hline BV & + & - & - & - & + & + & + & +++ & - \\
\hline
\end{tabular}

Optic nerve

\begin{tabular}{|c|c|c|c|c|c|c|c|c|c|}
\hline NF & + & + & + & - & + & - & + & - & + \\
\hline S & ++ & + & ++ & - & - & ++ & + & - & - \\
\hline BV & ++ & - & ++ & ++ & + & ++ & - & ++ & - \\
\hline
\end{tabular}

- negative reaction; + week reaction; ++ moderate reaction; +++ strong reaction. Ep $=$ Epithelium, Bm $=$ Bawman's membrane, St $=$ Stroma, Dm $=$ Descemet's membrane, En $=$ Endothelium, $\mathrm{PE}=$ Pigmented epithelium, NPE = Non pigmented epithelium, BV = Blood vessels, SM = Sphincter muscle, CM = Ciliary muscle, BL = Basal lamina, RPE = Retinal pigmented epithelium, R\&C = Rods and cones, ELM = External limiting membrane, $\mathrm{ONL}=$ Outer nuclear layer, OPL = Outer plexiform layer, INL = Inner nuclear layer, IPL = Inner plexiform layer, GCL= Ganglion cell layer, $\mathrm{NFL}=\mathrm{Nerve}$ fiber layer, ILM = Internal limiting membrtane, $\mathrm{S}=$ Septa, $\mathrm{NF}=$ Nerve fiber. 
Basal lamina and blood capillaries of the choroids reacted strongly with Con A, ECA, VVA and WGA. PNA. GSA I was bound strongly to all capillaries. Other lectins were not reacting with the choroid (Table 2 and Figure 4).

\section{Retina}

Histologically, the retina consists of following layers: pigment epithelium, layers of rods and cones, external limiting membrane, outer nuclear layer, outer plexiform layer, inner nuclear layer, inner plexiform layer, ganglion cell layer, optic nerve fiber layer, and internal limiting membrane.

WGA and Con A were bound strongly to all layers of the retina, mainly to the rods and cones (Figure 5A,B). LTA, SBA and UEA I did not give any reaction with retina.

In detail, the retina showed follows staining pattern: RPE revealed strong lectin binding sites for Con A, VVA WGA, and PNA (Figure $5 A, B)$, while GSA I agglutinen showed a weak reaction with RPE. Other lectins did not give any positive reaction with RPE. WGA, Con A, VVA and PNA were bound strongly to the rod and cone photoreceptor cells (Figure 5A,B). GSA I agglutinin reacted only strongly with the outer segment of the rods and cones (Table 2).

Con A, WGA, and PNA (Figure 5A,B) were bound strongly to the external and internal limiting membrane of the retina (Table 2), but the reaction was more prominent in external limiting membrane. Other lectins did not give any staining, neither of the external or the internal limiting membrane. Whereas WGA and Con A reacted weakly with both outer and inner nuclear layers of the retina. Con A was the only lectin which showed moderate binding to the ganglionic cell layer in retina. All others did not give any reaction.

WGA, Con A, VVA and PNA reacted weakly with the optical nerve fiber layer of the retina. GSA I agglutinin reacted strongly with the endothelium of all blood vessels in the retina Con A, VVA, WGA, and PNA (Figure 5A,B) showed the endothelium of the retinal blood vessels weakly. All other lectins were negative (Table 2)

\section{Optic nerve}

The optic nerve is formed by ganglion cell axons, glial cells and septa of connective tissue which arise from the pia mater. The area cribrosa is formed by lamellae of collagenous fibers which run in different directions forming a mesh like arrangement and are penetrated by the axons of the optic nerve.

In sagittal sections the bundles of the fibers of the optic nerve run parallel to each other separating by collagenous bundles septa of the area cribrosa. These bundles fade out in posterior directions.

Nerve fibers of the optic nerve were bound strongly to Con A, ECA, VVA and UEA I (Figure $6 \mathrm{~A}-\mathrm{C})$. There was no positive reaction with WGA, LTA, SBA and GSA I (Figure 6D,E).

Bundles of the collagen fibers of the connective tissue septa in the area cribrosa reacted strongly with Con A, WGA and ECA (Figure 6AD). They showed a weak reaction with LTA and PNA (Figure 6F) and did not stain with SBA and UEA I. Collagenous fibers are in the area cribrosa. The staining with ECA of the collagenous fibers from the area cribrosa was not particularly prominent. Blood capillaries of the optic nerve, reacted strongly with Con A, ECA, SBA, WGA and GSA I (Figure 6A-D) while bound weakly VVA, and no reaction was seen with LTA, PNA and UEA I.

\section{Discussion}

Glycoproteins occur mainly intracellular and may also be found in cell membranes with a variety of important biological functions. Lectins are sugar binding protein that can be useful for the localization of glycoproteins in cells. This could contribute to a better interpretation of the physiological and pathological processes in the corneal tissue. ${ }^{24}$

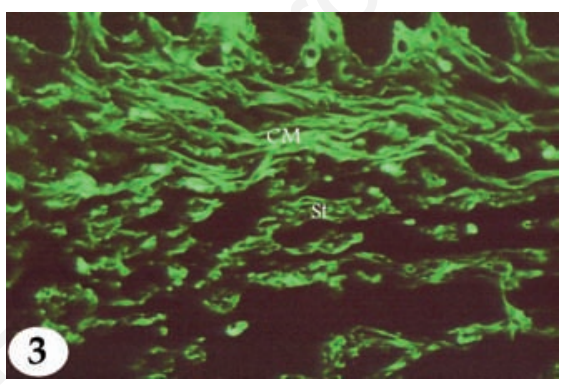

Figure 3. Lablling the ciliary musscle of the stroma of the donkey ciliary body with WGA $(\times 600)$.

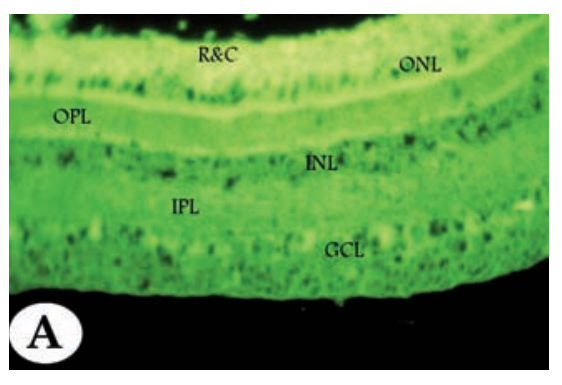

Post-translational glycosylation of proteins and lipids play an important role in the cellular functions. Lectin histochemistry enables the morphological evaluation of the distribution of the saccharide residues within the tissue sections. ${ }^{25}$ Thus, the present data, demonstrating the lectin binding sites in the donkey eyeball, propose a basis for further analyses of the role of saccharide residues in the eye under different experimental and pathological conditions.

The sugar residues play a role in maintaining the corneal structure. ${ }^{26}$ The pattern of lectin binding in the corneal epithelium suggests the presence of glycoconjugates containing terminal $\alpha$-mannose, $\mathrm{N}$-acetylglucosamine and sialic acid residues and sparse terminal $\alpha$ galactose and $\beta$-N-acetylgalactosamine residues. ${ }^{9,17,27,28}$ This generally agrees to my results.

Lectin binding to the cornea in different species, e.g. calf, has been studied previously by Panjwani and Baum, 1989.16 The results of this study are generally in accordance with their findings but there are also some differences. Panjwani and Baum, ${ }^{10}$ mentioned that Con A and PNA were bound to the corneal epithelium, whereas our results showed that Con A was bound throughout all epithelial layers of the cornea. Also PNA was bound mainly

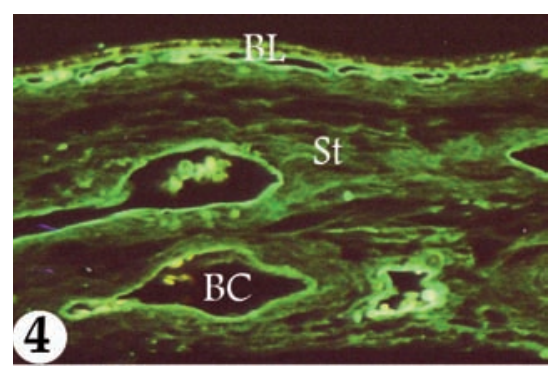

Figure 4. Lablling of the donkey choroid layers; the endothelium of the blood capillaries stroma and basal lamina with WGA $(\times 600)$.

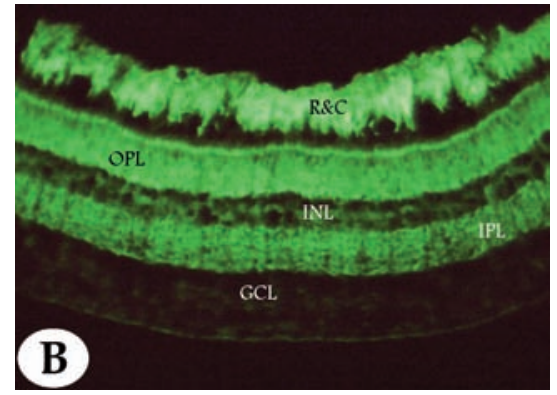

Figure 5. A) labelling of the layer of rods and cones (R\&C), outer nuclear layer (ONL), outer plexiform layer (OPL), Inner nuclear layer (INL), inner plexiform layer (IPL) and Ganglion cell layer (GCL) of the donkey retina with Con A $(\times 600)$; B) labelling of the layer of R\&C, OPL, INL and IPL of the donkey retina with WGA $(\times 600)$. 
to the apical epithelial cells, 15 rather than to basal cells as demonstrated in my study. Our results are different from the findings of Tuori et al,11 who reported no binding of the Con A and PNA to the corneal epithelium. Tuori $e t$ $a l .11$ demonstrated that WGA, UEA-I and GSA-I were bound to the corneal epithelium and that apical cells of the epithelium of the cornea displayed more $\alpha$-GalNAc, GlcNAc, sialic acid and $\alpha$-L-Fuc residues than the basal cells. This agrees to our results. The different staining pattern between apical and basal cells of the corneal epithelium has been described previously by several authors in different species, $6,9,24,27$ and it is related to the differentiation of epithelial cell, as they move to the apical layers of the epithelium..$^{29}$ Furthermore, Con A and WGA were bound to the corneal stroma in my experiment, but no binding of this lectins was seen in the study of Panjwani and Baum, ${ }^{16}$ who reported that PNA is the only lectin that is bound to the corneal stroma. This result is in the findings of Tuori et al., ${ }^{11}$ and ours. Our findings on corneal tissue do not parallel those of Spiro and Bhoyroo, 30 but show excellent correlation with results of Panjwani and Baum. ${ }^{10}$ The observed species differences in the expression of the corneal stromal GSA-I binding sites probably do not reflect differences in blood group antigens among different species, because, at least in humans, such antigens are not found in stromal matrix or on stromal cells.

Con A and WGA were bound to the Descemet's membrane of the donkey cornea. This result is generally in accordance with the studies of Panjwani and Baum, 10 and Tuori $e t$ $a l ., 11$ but with a little difference. Con A reacted with the anterior part of the Descemet's membrane, while WGA reacted mainly with the posterior border of the Descemet's membrane. Heterogeneity in the distribution of the glycoproteins within the Descemet's membrane has been demonstrated previously. ${ }^{13,28,31}$ The thin basement membranes showed a marked presence of $\mathrm{N}$-acetylgalactosamine residues, whereas a low concentration of these sugar residues was found in thick basement mem- branes. 32 Our observations showed binding of Con A and WGA to the corneal endothelium. This finding is not in accordance with the results of Panjwani and Baum, 10 Tuori et al.,11 who reported that the corneal endothelium tend to be bound only GSA-I-B4.

Some of the results from previous lectin binding studies in the human cornea are somewhat different in various investigations. ${ }^{9}, 17,24,33$

Brandon et al.,33 suggested that some of the variation in the histochemical lectin binding studies is due to different staining procedures or post-mortem changes of the tissues. This could also explain the difference observed between our investigation and the studies of Panjwani and Baum, ${ }^{10}$ and Tuori et al. 11

PNA is a lectin which preferentially detects $\alpha$-galactose. It is also used as a biological marker to detect the T antigen. Due to the neoexpression of $\mathrm{T}$ antigen in malignant cells, PNA and other lectins of the same specificity have been used as tools in the diagnosis of cancer. In my work, PNA reacted weakly with
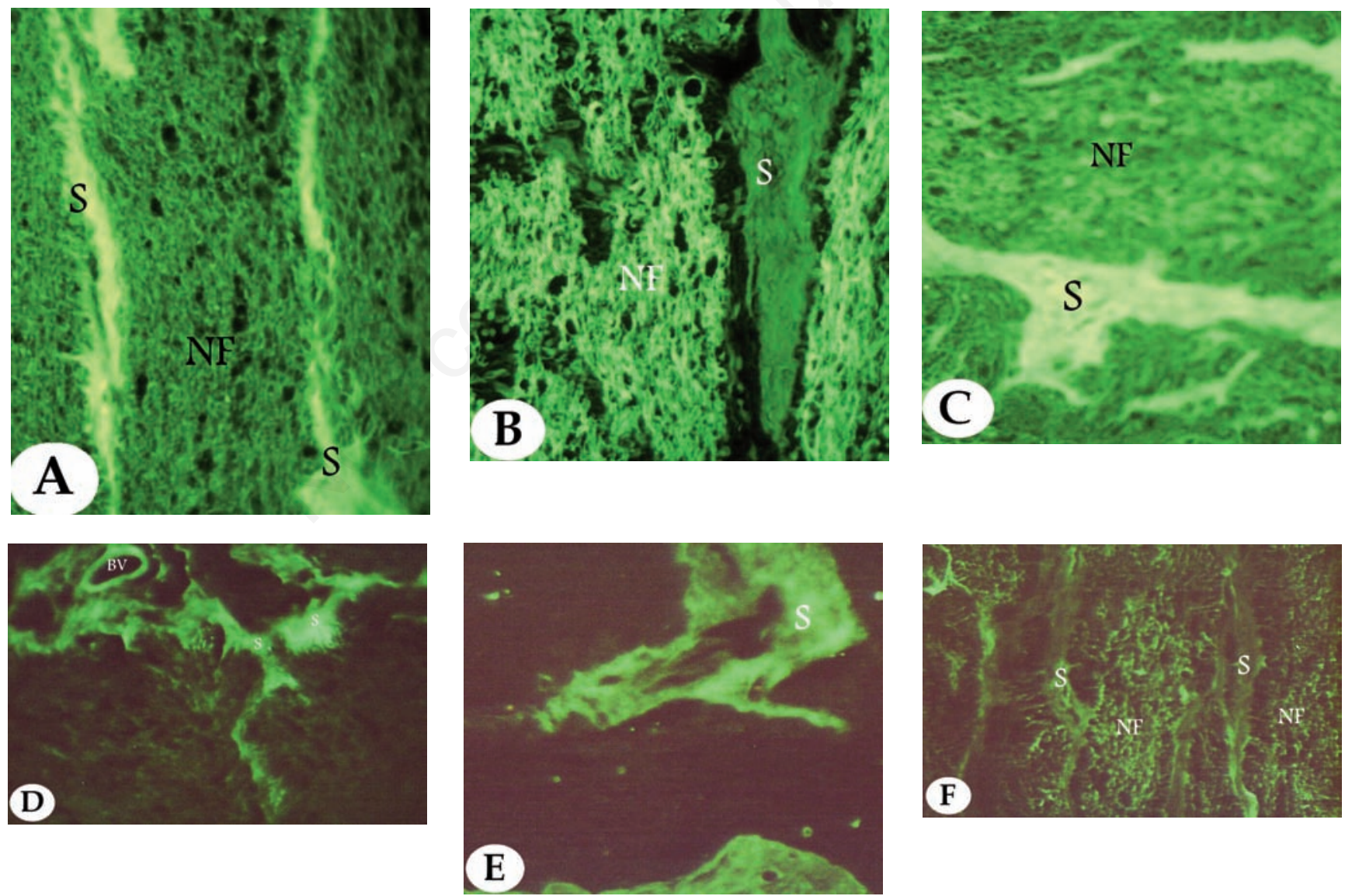

Figure 6. A) Labelling of the nerve fiber (NF) and connective tissue septa (S) of the donkey optic nerve with Con A ( $\times 600$ ); B) labelling of NF and connective tissue septa of the donkey optic nerve with VVA $(\times 600)$; C) labelling of the NF and connective tissue $S$ of the donkey optic nerve with ECA $(\times 600)$; D) labelling of the connective tissue $S$ and endothelium of blood vessels (BV) of the donkey optic nerve with WGA $(\times 600)$; E) labelling of the connective tissue $S$ of the donkey optic nerve with GSA I $(\times 600)$; F) weak labelling of the NF and connective tissue $S$ of the donkey optic nerve with PNA $(\times 600)$. 
the donkey cornea.

Contrary Con A, WGA and PNA showed a distinct reactivity with Bowman's membrane, showing $\alpha$-mannose, $\mathrm{N}$-acetylglucosamine and $\alpha$-galactose residues in this structure.

The lectin binding to the sclera did not differ significantly to that of the stroma of the cornea.

The binding of lectins to the blood vessels of the anterior uvea demonstrates the presence of glcoconjugates containing terminal $\mathrm{N}$ acetylglucosamine and $\alpha$-galactose in the vascular endothelium. The weak staining with these lectins revealed also the presence of some $\alpha$-mannosyl, $\mathrm{N}$-acetylgalactosamine and sialic acid residues in the endothelium. The vascular endothelium has been previously studied using some of these lectins in bovine tissues. ${ }^{11,34}$ Our demonstration of the presence of $\alpha$ - and $\beta$ - galactose and sialic acid and the absence of fucose are in agreement to the results of Alroy et al., ${ }^{34}$ and Tuori et al., $11 \mathrm{We}$ also found mannose residues in the endothelium similar to finding of Tuori et al.,11 and in contrast to the results of Alroy et al. ${ }^{34}$ Previous studies have suggested that GSA-I-B4 is an endothelial marker in mouse tissues in the same way as UEA-I is for human tissues. 35,36 The present results show that GSA-I is and endothelium marker in donkey tissues and these findings are in accordance with observations of Tuori et al.11

The stroma of the iris is abundant in collagen fibers. They were stained by Con A, ECA, VVA, WGA and PNA. The presence of sialic acid and $\beta$-galactose has been noticed previously by Pena et al. ${ }^{37}$ Similar results were also obtained by Tuori $e t$ al.

The posterior pigmented epithelial cell membrane of the iris and the nonpigmented epithelium cell of the ciliary body have $\alpha$-mannose and $\mathrm{N}$-acetylglucosamine residues. This is in accordance with the studies of Tuori et al.

A-mannosyl and $\mathrm{N}$-acetylglucosamine residues are abundant in the donkey iridal and ciliary muscle, whereas the Gal- $(\beta 1,3)-\mathrm{N}$ GalNAcresidues are also present in the ciliary muscle. Identical results were obtained by Tuori et al. Lectin histochemistry has been applied to human and rat skeletal muscle previously and it has been shown that Con A reacted with muscle cells whereas UEA-I was negative. ${ }^{37}$ However, the other lectins are used in the present study (PNA and WGA) stained iridal and ciliary smooth muscle cells differently.

The results of my study show clearly that specific structures in the donkey retina can be stained with different lectins (Table 1). The binding of the retinal structures was dependent on the sugar-binding specificities of the different lectins, demonstrating the presence of different glycoconjugates in specialized parts of the retina.

The binding of Con A and WGA to donkey retinal structures is in agreement to previous studies in the frog, 38 in the monkey, ${ }^{39}$ and in human. ${ }^{40}$ However, there are some differences in the staining pattern of PNA and UEA-I that may result from species differences or from variation in tissue preparation, which are known to affect lectin histochemistry. 41,42

In my study, normal donkey retinal pigmented epithelium showed lectin binding sites for Con A, WGA, VVA and PNA. These results are in accordance with the findings of Bopp et al., ${ }^{43}$ in human retinal pigmented epithelium.

The biochemical role of lectin binding sites in RPE still remains unclear, especially the significance of the presence or absence of certain cellular sugar residues for structure and function of RPE-cells. ${ }^{42}$ Con A also is bound with high affinity to rhodopsin, the photoreceptor molecules of the rods. $44-46$

Rhodopsin contains a special oligosaccharide-chain GlcNAc $\beta 1-2 M a n$ 1-3(Man 1-6) Man $\beta 1-4 G l c N a c \beta 1-4 G l c N a c-A s n .44,46$ Its high content of both terminal $\mathrm{N}$-acetylglucose and mannose residues explain the binding of Con A to the rods in donkey retina. Thus, the distribution of Con A-binding sites in donkey rods might reflect the distribution of rhodopsin within these cells. However, there are also other glycoconjugates in the rods, such as the outer segment protein, with a molecular weight of $291,000,47,48$ and the glycoprotein of the interphotoreceptor matrix that bind Con A and WGA. 49

Rod and cone discs are formed by infolding of the plasma membrane. In the rods these infoldings are sealed off to form stacks of flattened bimembranous discs, so that the oligosaccharide layer that normally resides on the extracellular surface is sequestrated into the disc interior. 50

Con A stained material in the donkey rods seemed to be intracellularly located and its concentration was higher in the outer segments than in the inner segments.

There are membranous disks inside the rod outer segment that contains rhodopsin. 51,52 It has been suggested that the rod outer segments bind fucosyl and galactosyl residues prior to disk shedding and phagocytosis by the cells of the pigment layer. ${ }^{53,54}$ In this way the cells of the pigment layer can recognize the differences between shed and intact disks. Previous studies have given conflicting results concerning this theory. In the monkey retina, RCA I, which identifies terminal galactosyl residues, binds to the outer segments of the rods, indicating the presence of galactosyl residues. However, in the monkey retina, UEA I and LTA which identify fucosyl residues bind only to the inner segments of the rods and cones. ${ }^{39,55}$ In our study we could not find any binding of ECA, UEA I or LTA in the rods. These findings are in accordance with those of Bridges, 18 and could be due to species differ- ences, indicating a different processing of rhodopsin in different species. However, in the rods of the frog, RCA I staining is seen on the surface of the outer segments. ${ }^{46}$ Those studies were done with cell suspensions in which the cell surface is easier to study. In the present investigation tissue sections were used. The stained material is primarily intracellular. If the cell surface is only slightly stained, it may be difficult to observe it in tissue sections. Sheets and occasional chunks of this matter were sometimes found on the detached retina and probably represent the interphotoreceptor matrix, which is known contain fucose residues. 56

Since Con A and WGA are also bound to the outer segment of the cones. Their visual pigments may contain sugar sequences that resemble those found in rhodopsin, and show different lectin affinities. For instance, rhodopsin and iodopsin both are bound to Con A columns but they are eluted at different concentrations of -methyl-mannopyranoside. .57

WGA is bound to terminal GlcNac or sialic acid residues. ${ }^{58}$ WGA is not bound to rhodopsin, ${ }^{59}$ so the binding of WGA to the retina must be explained by the presence of other glycoconjugates. These are present in the cytoplasm of the rods and cones but are not seen in the internal segment of the cones. Quite interesting is the band-like staining by WGA within the outer plexiform layer, for which no clear morphological equivalents can be seen with conventional staining methods.

Lectin PNA is known to have high affinity for $\alpha$-D-galactose and $\mathrm{N}$-acetylgalactosamine. ${ }^{60}$ It is, therefore, possible to assume that these carbohydrate residues are present at the terminal oligosaccharides of membrane glycoconjugates in rods and cones. Concerning the binding sites of PNA, it is noticeable that the labelling was uniform throughout the outer and inner segments of rods and cones.

In the monkey retina, PNA also selectively stained the cones, but the binding was concentrated to the outer segment. ${ }^{61}$ Their was also found in human, 40 in pig and cat and in rabbit retina. ${ }^{22}$ These observations are different to our results. We showed that PNA bound strongly with rods and cones layer. Our finding agree with results which reported by Kawano et al., ${ }^{22}$ that mammals including rat and bovine and non-mammals including birds and goldfish strongly bound PNA to rods and cones.

In addition to the layer of the rods and cones, Con A stained many other structures of the retina. The external and internal limiting membrane was only slightly stained whereas in the outer nuclear layer, where the nuclei of the rods and cones are located. The cell surfaces of the neurons in the inner nuclear layer were marked. Both inner and outer plexiform layers were diffusely stained with Con A. This finding agrees with results in the human reti- 
na. ${ }^{40}$ The internal and external limiting membranes and the wall of the retinal vessels are labelled with PNA. The vessel wall contains collagen fibrils which are abundant in $\alpha$-galactose. 62,63

\section{Conclusions}

In summary, our study shows that the normal donkey eye contains a distinct distribution pattern for several lectins. These results on the normal donkey eye may form the basis for future studies concerning changes in lectin staining occurring in different diseases of the eye.

\section{References}

1. Töpfer-Petersen E. Carbohydrate-based interactions on the route of a spermatozoon to fertilization. Hum Reprod 1999;5:314-29.

2. Gabius HJ. Glycohistochemistry: the why and how of detection and localization of endogenous lectins. Anat Histol Embryol 2001;30:3-31.

3. Hakomori S. Glycosphingolipids in cellular interaction, differentiation, and oncogenesis. Ann Rev Biochem 1981;50:733-64.

4. Gabius HJ, Rüdiger H, Uhlenbruck G. Lektine. Spektrum Wiss 1988:50-60

5. Goldstein IJ, Poretz RD. Isolation, physicochemical characterization, and carbohydrate- binding specificity of Lectins. In: Liener IE, Sharon N, Goldstein IJ eds. The Lectins: properties, functions, and applications in biology and medicine. New York Academy Press; 1986. pp 35-244.

6. Gipson KI, Riddle CV, Kiorpes TC, Spurr SJ. Lectin binding to cell surfaces: comparisons between normal and migration corneal epithelium. Dev Biol 1983;96:33745.

7. Beauchamp GR, Lubeck D, Kuepper PA. Glycoconjugates, cellular differentiation, and congenital glaucoma. J Pediatr Ophthalmol Strabismus 1985; 22:149-55.

8. Holmes MJ, Mannis MJ, Lund J, Jacobs L. Lectin receptors in the human cornea. Cornea 1985;4:30-4.

9. Panjwani N, Moulton P, Alroy J, Baum J. Localization of lectin binding sites in human, cat, and rabbit corneas. Invest Ophthalm Vis Sci 1986;27:1280-4.

10. Panjwani N, Baum J. A histochemical comparison of human corneal stromal glycoconjugates with eight other species. Distinct species-dictated differences in binding sites of Griffonia simplicifolia I. Histochemistry 1988;89:41-5.
11. Tuori A, Virtanen I, Uusitalo H. Lectin binding in the anterior segment of the bovine eye. Histochem J 1994;26:787-98.

12. Aly K. Glycohistochemical, immunohistochemical and electron microscopic examination of the bovine eyeball. PhD dissertation. Institute of Veterinary Anatomy II, Faculty of Veterinary Medicine, LMU, Munich, Germany. 2003.

13. Gordon SR, Marshand J. Lectin binding to injured corneal endothelium mimics patterns observed during development. Histochemistry 1990;94:455-62.

14. Panjwani N, Rodrigues MM, Alroy J, et al. Alterations in stromal glycoconjugates in macular dystrophy. Invest Ophthalm Vis Sci 1986;27:1211-6.

15. Panjwani N, Rodrigues M, Free K, et al. Lectin receptors of amyloid in cornea with lattice dystrophy. Arch Ophthalm 1987;105:688-91.

16. Panjwani N, Baum J. Lectin receptors of normal and dystrophic corneas. Acta Ophthalmol 1989;67 Suppl 192:171-3.

17. Bishop PN, Bonshek RE, Jones CJP, et al. Lectin binding sites in normal, scarred, and lattice dystrophy corneas. $\mathrm{Br} \mathrm{J}$ Ophthalmol 1991;75:22-37.

18. Bridges CD. Lectin receptors of rods and cones. Visualization by fluorescent label. Invest Ophthalm Vis Sci 1981;20:8-16.

19. Blanks JC, Johnson LV. Specific binding of peanut lectin to a class of retinal photoreceptor cells. A species comparison. Invest Ophthalmol Vis Sci 1984;25:546-57.

20. Johnson LV, Hageman GS. Enzymatic characterization of peanut agglutinin-binding components in the retinal photoreceptor matrix. Exp Eye Res 1987;44:553-65.

21. Chan FL, Poon HK, Huang Y, Choi HL. Glycoconjugates of the rat ciliary body epithelium: a lectin histochemical and protein blotting study. Histochem J 1999;31:95-107.

22. Kawano K, Uehara F, Sameshima M, Ohba $\mathrm{N}$. Binding sites of peanut agglutinin in mammalian retina. Jpn J Ophthalmol 1984;28:205-14.

23. Prause JU. Lectins in ophthalmology and ophthalmic pathology. In: Kilpatrick E, ed. Lectin reviews. Vol. 1. St Louis: Sigma Chemical Company; 1991. pp 203-213.

24. Bonvicini R, Versura P, Caruso F, et al. Lectin receptors on human corneal epithelium. Visualization by fluorescence and electron microscopy. Cornea 1983;2:23741.

25. Spicer SS, Schulte BA. Diversity of cell glycoconjugates shown histochemically: a perspective. J Histochem Cytochem 1992;40:1-38.

26. Mencucci R, Marini M, Gheri G, et al. Lectin binding in normal, keratoconus and cross-linked human corneas. Acta
Histochem 2011;113:308-16.

27. Rittig M, Brigel C, Lütjen-Drecoll E. Lectinbinding sites in the anterior segment of the human eye. Graefes Arch Clin Exp Ophthalmol 1990;228:528-32.

28. Lawrenson JG, Reid AR, Allt G. Corneal glycoconjugates: an ultrastructural lectingold study. Histochem J 1998;30:51-60.

29. Nemanic MK, Whithead JS, Elias PE. Alterations in membrane sugars during epidermal differentiation. J Histochem Cytochem 1983;31:887.

30. Spiro RG, Bhoyroo VD. Occurrence of $\alpha$-Dgalactosyl residues in the thyroglobulins from several species. J Biol Chem 1984;259:9858-66.

31. Ljubimov AV, Burgeson RE, Butkowski RJ, et al. Human corneal basement membrane heterogeneity: topographical differences in the expression of type IV collagen and laminin isoforms. Lab Invest 1995;72:46173.

32. Salamat M, Götz W, Werner J, Herken R. Ultrastructure localization of lectin-binding sites in different basement membranes. Histochem J 1993;25:464-8.

33. Brandon DM, Nayak SK, Binder PS. Lectin binding patterns of the human cornea, comparison of frozen and paraffin sections. Cornea 1988;7:257-66.

34. Alory J, Goyal V, Skutelsky E. Lectin histochemistry of mammalian endothelium. Histochemistry 1987;86:603-7.

35. Laitinen L, Virtanen I, Saxen L. Changes in the glycosylation pattern during embryonic development of mouse kidney as revealed with lectin conjugates. J Histochem Cytochem 1987;35:55-65.

36. Holthöfer H, Virtanen I, Karinieni AK, et al. Ulex europaeus I lectin as a marker for vascular endothelium in human tissues. Lab Invest 1982;47:60-6.

37. Pena SD, Gordon BB, Karpati G, Carpenter S. Lectin histochemistry of human skeletal muscle. J Histochem Cytochem 1981;29: 542-6.

38. Bridges CD, Fong SL. Different distribution of receptors for peanut and ricin agglutinins between inner and outer segments of rod cells. Nature 1979;82:513-5.

39. Uehara F, Muramatsu T, Sameshima M, et al. Identificationof peanut agglutinin receptors in the monkey retina. Exp Eye Res 1989;37:303-5.

40. Söderström K. Lectin binding to the human retina. Anat. Rec 1988;220:219-23.

41. Brasitus TA, Goldfarb JP, Hus KC, Tannenbaum M. Characterization of rat colonic cell surface glycoconjugates by fluoresceinated lectins. I. Importance of fixation techniques. Histochemistry 1982;76: 197-209.

42. Söderström KO, Malmi R, Karjalainen K. Binding of fluorescein isothiocyanate con- 
jugated lectins to rat spermatogenic cells in tissue sections. Enhancement of lectin fluorescence obtained by fixation in Bouin's fluid. Histochemistry 1984;80:4759.

43. Bopp S, El-Hifnawi E, Laqua H. Lectin binding pattern in human retinal pigmented epithelium. Ann Anat 1992;174:279-85.

44. Fukuda MN, Papermaster DS, Hargrava PA. Rhodopsin carbohydrate. Structure of small oligosaccharides attached at two sites near the NH2 terminus. J Biol Chem 1979;254:8201.

45. Liang CJ, Yamashita K, Shichi H, et al. Structure of the carbohydrate moieties of bovine rhodopsin. J Bio Chem 1979;254:6414.

46. Bridges CD, Fong SL. Lectins as probes of glycoprotein and glycolipid oligosaccharides in rods and cones. Neurochemistry 1980;1:255.

47. Dreyer WJ, Papermaster DS, Kuhn H. On the absence of ubiquitous structural protein subunits in biological membranes. Ann NY Acad Sci 1972;195:61.

48. Bownds D, Brodie A, Robinson WE, et al. Physiology and enzymologyof frog photoreceptor membranes. Exp. Eye Res 1974;18:153.

49. Adler AJ, Klucznik KM. Proteins and glycoproteins of the bovine interphotoreceptor matrix: comparison and fractionation. Exp Eye Res 1982;34:423-34.

50. Hirano H, Parkhous B, Nicolson GL, et al. Distribution of saccharides residues on membrane fragments from a myeloma cell homogenate: its implications for membrane biogenesis. Proc Natl Acad Sci USA 1972;69:2945.

51. Jan LY, Revel J. Ultrastructure localization of rhodopsin in the vertebrate retina. $\mathrm{J}$ Cell Biol 1974;62:257-73.

52. Basinger S, Bok D, Hall MO. Rhodopsin in the rod outer segment plasma membrane. J. Cell Biol 1976;69:29-42.

53. McLaughlin BJ, Wood JG. The localization of lectin binding sites on photoreceptor outer segment and pigment epithelium of dystrophic retinas. Invest Ophthalmol Vis Sci 1980;19:728-42.

54. 0’Brien PJ. Rhodopsin as a glycoprotein: a possible role for the oligosaccharide in phagocytosis. Exp Eye Res 1976;23:127-37.

55. Bunt AH, Klock IB. Comparative study of ${ }^{3} \mathrm{H}$-fucose incorporation into vertebrate photoreceptor outer segments. Vision Res 1980;20:739-47.

56. Feeney L. Synthesis of interphotoreceptor matrix. I. Autoradiography of ${ }^{3} \mathrm{H}$-fucose incorporation. Invest Ophthalmol 1973;12:739-51.

57. Fager LY, Fager RS. Separation of rod and cone pigments from the chicken retina. Invest. Ophthalmol Vis Sci 1978;17:126.

58. Goldstein IJ, Hayes CE. The lectins: carbohydrate binding proteins of plants and animals. Adv Carbohydr Chem Biochem 1978;35:127-340.

59. Yamamoto K, Tsuji T, Matsumoto I, Osawa T. Structural requirement of the binding of oligosaccharides and glycopeptides to immobilized wheat germ agglutinin. Biochemistry 1983;20:5894-9.

60. Lotan R, Skutelsky E, Danon D, Sharon N. The purification,composition, and specificity of the anti-T lectin from peanut (Arachis hypogaea). J Biol Chem 1975; 250:8518-23.

61. Uehara F, Sameshima M, Muramatsu T, Ohba N. Localization of fluorescencelabelled lectin binding sites on photoreceptor cells of the monkey retina. Exp Eye Res 1983;36:113-23.

62. Hogan MJ, Alvarado JA, Weddell JE. Histology of the human eye. Philadelphia: WB Saunders; 1971.

63. Muir L, Lee YC. Structure of the D-galactose oligosaccharides from earthworm cuticle collagen. J Biol Chem 1969;244: 2343-9. 